\title{
Weight management experiences of overweight and obese Canadian adults: findings from a national survey
}

\author{
S. F. Kirk, PhD (1); R. Tytus, MD (2); R. T. Tsuyuki, MD (3); A. M. Sharma, MD (3)
}

This article has been peer reviewed.

\begin{abstract}
Introduction: We know little about how the 2006 Canadian Clinical Practice Guidelines for the management and prevention of obesity relate to Canadians' weight management experiences or whether these experiences reflect the recommendations in the Guidelines.

Methods: We used data from a general population omnibus survey to understand these two issues, particularly in relation to chronic disease. The survey included 23 questions related to weight management practices as well as those related to demographic characteristics.
\end{abstract}

Results: Of 2004 respondents, 33\% were classified as overweight and $20 \%$ as obese. In the 12 months before the survey, $48 \%$ of overweight and obese respondents reported asking their physician about weight loss, while $30 \%$ reported that their physician advised them to lose weight without them specifically asking. With regard to the recommendations within the Guidelines, $14 \%$ of overweight and $18 \%$ of obese respondents reported having their waist circumference measured, $82 \%$ of overweight and $87 \%$ of obese respondents reported having their blood pressure measured, and $36 \%$ of overweight and $50 \%$ of obese respondents reported having a test for diabetes.

Conclusion: These findings have implications for chronic disease identification and management.

Keywords: overweight, obesity, clinical practice guidelines, diabetes, hypertension, chronic disease

\section{Introduction}

Obesity rates in Canada, as in other parts of the developed world, have increased dramatically over the last few decades. ${ }^{1,2}$ Since obesity is strongly linked to a number of chronic diseases, including diabetes, coronary heart disease and hypertension, ${ }^{1}$ rates of these are on the increase. As a result, the sustainability of the Canadian health care system is significantly affected. ${ }^{3}$ A recent analysis estimated the total direct costs attributable to overweight and obesity at $\$ 6.0$ billion, which corresponds to $4.1 \%$ of total Canadian health care expenditures. $^{3}$

Canadians with a body mass index (BMI) greater than $30 \mathrm{~kg} / \mathrm{m}^{2}$ are 4 times as likely to have diabetes, 3.3 times as likely to have high blood pressure and 1.5 times as likely to have heart disease. ${ }^{1}$ A recent US study suggested that, given the marked increase in the proportion of obese people, obesity has become an equal if not greater contributor to the burden of disease than smoking. ${ }^{4}$ Further, compared to baseline rates the prevalence of Class II (BMI $35-39.9 \mathrm{~kg} / \mathrm{m}^{2}$ ) and Class III obesity $\left(\mathrm{BMI} \geq 40 \mathrm{~kg} / \mathrm{m}^{2}\right.$ ) in Canada has shown the biggest increase. ${ }^{5}$ In other words, those who are overweight or obese-the very individuals at greater risk of these comorbidities-are getting heavier faster. ${ }^{4}$

Yet, despite these stark statistics, obesity is not well managed within the current health system, a situation not unique to Canada. ${ }^{6,7}$ Few health care professionals advise their patients about weight management in general or provide obesity management services. ${ }^{8}$ Indeed, many Canadian health care professionals fail to even raise the issue of obesity with their patients. ${ }^{9}$ Against this backdrop, publication of the 2006 Canadian Clinical Practice Guidelines for the management and prevention of obesity marked an important milestone in addressing obesity. ${ }^{10}$ These Guidelines aim to effect change in clinical practice and ultimately decrease the prevalence of obesity and its complications among Canadians. ${ }^{11}$ They make 72 recommendations to support obesity management across a range of settings, emphasizing the role of health care professionals within the Canadian health care system.

We know very little about the current weight management experiences of Canadians; nor do we know whether their experiences reflect the recommendations within the Guidelines. Understanding more about the weight management experiences of overweight and obese people could encourage them to seek appropriate 
weight management support. In addition, insight into these individuals' experiences in relation to the recommendations in the Guidelines may shed light on the weight management practices of health care professionals and help improve their application of the Guidelines. Given the large number of recommendations in the Guidelines, it is not feasible to measure them all within routine clinical practice. However, there are three that are particularly relevant to chronic disease identification and management. ${ }^{10}$ These are No. 4 , which recommends the measuring waist circumference in all adults to assess obesity-related health risks, and Nos. 6 and 7, which address the need to screen for obesityrelated health risks and complications. ${ }^{10}$ Reporting the weight management practices associated with these three recommendations by overweight and obese individuals therefore serves as a proxy measure of implementation of the Guidelines by health care professionals.

\section{Methods}

This survey sought to determine the weight management experiences of Canadian adults, that is, whether those who are overweight or obese (1) reported seeking support from family physicians or other health care professionals for weight management; and (2) reported weight management experiences that reflected three recommendations from the guidelines, namely measuring waist circumference (recommendation No. 4) and screening for weight-related comorbidities such as hypertension or diabetes (recommendations Nos. 6 and 7).

On behalf of the federally funded Canadian Obesity Network, Ipsos Reid conducted a general population omnibus survey over two consecutive weeks between March $23^{\text {rd }}$ and April $3^{\text {rd }}$, 2009. Each one-week wave of the survey involved around 1000 adult Canadians. An independent panel of experts developed the interview questions, including 23 related to weight management practices as well as those related to demographic characteristics, including self-reported height and weight, gender, age, income and region of residence. Canadian SHIELD Ethics Review Board gave ethical approval. The sample size was chosen to provide robust data from a representative cross-section of the population based on key demographic criteria (e.g. sex, age, location). ${ }^{12}$

Interviews were conducted using a computer-aided telephone interview (CATI) system and random digit-dialing. Data were weighted to be nationally representative of all adults aged 18 years plus and balanced to match the most recent Statistics Canada figures for sex, age, income and region of residence. ${ }^{12}$ The proportions and means were statistically compared within 5\% significance level $(p<.05)$. BMI was calculated based upon self-reported height and weight and respondents were categorized as underweight $\left(<18.5 \mathrm{~kg} / \mathrm{m}^{2}\right)$; normal weight (18.5-24.9 $\left.\mathrm{kg} / \mathrm{m}^{2}\right)$; overweight $\left(25-29.9 \mathrm{~kg} / \mathrm{m}^{2}\right)$; and obese $\left(\geq 30 \mathrm{~kg} / \mathrm{m}^{2}\right.$ ). In addition, two further categories, BMI of $27 \mathrm{~kg} / \mathrm{m}^{2}$ plus with comorbidities and BMI of $30 \mathrm{~kg} / \mathrm{m}^{2}$ plus without comorbidities, were calculated. These categories represent established cut-offs as outlined in the Guidelines document. ${ }^{10}$ As the focus of the survey was weight management experiences in relation to overweight and obesity, data on the small number of underweight respondents $(\mathrm{n}=52)$ are not reported separately in this analysis.

\section{Results}

\section{Sample characteristics}

A total of 2004 survey respondents were included in the analysis. Of these, $48 \%$ were men $(\mathrm{n}=970)$ and $52 \%$ women ( $\mathrm{n}=1034) ; 78 \%$ were interviewed in English ( $\mathrm{n}=1557)$ and $22 \%$ in French $(\mathrm{n}=447)$. The mean age of respondents was 47 years (standard deviation of 16.4); 28\% were younger adults (18-34 years; $\mathrm{n}=559$ ), $39 \%$ were middle-aged (35-54 years; $n=788$ ) and $32 \%$ were older adults ( $\geq 55$ years; $\mathrm{n}=649)$. Seven respondents declined to give their age. Of the sample, $81 \%$ of were classified as urban dwellers ( $\mathrm{n}=1615$ ), while $19 \%$ were rural dwellers $(n=388)$. The mean BMI was $26.5 \mathrm{~kg} / \mathrm{m}^{2}\left(27.3 \mathrm{~kg} / \mathrm{m}^{2}\right.$ for men and $25.7 \mathrm{~kg} / \mathrm{m}^{2}$ for women), with $32 \%$ of respondents classified as overweight ( $\mathrm{n}=651$ ) and $21 \%$ as obese ( $\mathrm{n}=411$ ). Nevertheless, 44\% described their weight as "about right" ( $n=874$ ) and $37 \%$ described themselves as slightly overweight ( $\mathrm{n}=734$ ), with only $3 \%$ describing themselves as obese $(n=51)$. This pattern was generally consistent regardless of sex or age. Of those classified as overweight, $38 \%$ rated themselves as "about right" ( $\mathrm{n}=248 / 651$ ); of those classified as obese, $4 \%$ rated themselves as "about right" ( $\mathrm{n}=18 / 411)$; and of those classified as normal weight, $73 \%$ correctly described their weight as "about right” ( $\mathrm{n}=567 / 779$ ). Of those surveyed, $41 \%$ reported that they had never tried to lose weight ( $\mathrm{n}=818$ ). More women (52\%) than men $(37 \%)$ had tried to lose weight in the previous 12 months; this difference increased with increasing age, with a similar pattern reported by those who tried to lose weight more than 12 months before the survey.

\section{Objective 1: Weight management experiences of Canadians}

We sought to determine whether overweight or obese Canadian adults reported seeking support from family physicians or other health care professionals for weight management. The majority of overweight ( $\mathrm{n}=418 / 651 ; 64 \%$ ) and obese ( $\mathrm{n}=363 / 411 ; 88 \%$ ) respondents had tried to lose weight, most during the previous 12 months, with similar rates for those with a BMI of $30 \mathrm{~kg} / \mathrm{m}^{2}$ plus without comorbidities (ever tried losing weight; $\mathrm{n}=188 / 221 ; 85 \%$ ) and BMI of $27 \mathrm{~kg} / \mathrm{m}^{2}$ plus with comorbidities (ever tried losing weight; $n=253 / 293 ; 86 \%$ ). Differences in having tried to lose weight within the previous 12 months were significant for overweight compared with normal weight respondents, and for obese compared with normal weight and overweight respondents. Table 1 shows the characteristics of survey respondents' weight management experiences.

The majority of respondents ( $\mathrm{n}=1711$; $85 \%$ ) had seen a physician (for any condition, not specifically because of their weight) at least once in the 12 months before the survey. The proportions were generally similar among all groups, although some patterns were apparent; more women $(90 \%)$ than men $(80 \%)$, a greater percentage of the oldest age group ( $\geq 55$ years; $91 \%$ ) than the two younger age groups (18-34 years; 35-54 years; 
TABLE 1

Characteristics of survey respondents' visits to a physician and weight loss attempts

\begin{tabular}{|c|c|c|c|c|c|c|c|c|}
\hline \multirow{2}{*}{$\begin{array}{l}\text { Respondent } \\
\text { categories }\end{array}$} & \multirow{2}{*}{$\begin{array}{c}\text { Sample size, } \\
\mathbf{n}\end{array}$} & \multicolumn{3}{|c|}{ Visits to physician } & \multicolumn{4}{|c|}{ Weight loss attempts } \\
\hline & & $\begin{array}{c}\text { Seen a } \\
\text { physician in the } \\
\text { past } 12 \text { months }{ }^{\mathrm{a}} \text {, } \\
\mathrm{n}(\%)\end{array}$ & $\begin{array}{c}\text { Mean no. of } \\
\text { times seen a } \\
\text { physician }^{\text {b }}\end{array}$ & $\begin{array}{c}\text { Under physician's } \\
\text { care for } \\
\text { any condition, } \\
\text { n (\%) }\end{array}$ & $\begin{array}{l}\text { Last tried to lose } \\
\text { weight in the } \\
\text { past } 12 \text { months, } \\
n(\%)\end{array}$ & $\begin{array}{r}\text { Last t } \\
\text { lose we } \\
12 \text { mor } \\
\text { n }\end{array}$ & $\begin{array}{l}\text { ied to } \\
\text { ght over } \\
\text { ths ago, } \\
\% \text { ) }\end{array}$ & $\begin{array}{c}\text { Never tried to } \\
\text { lose weight, } \\
\text { n (\%) }\end{array}$ \\
\hline Allc & 2004 & $1711(85 \%)$ & 2.86 & $808 \quad(40 \%)$ & $897 \quad(45 \%)$ & 283 & $(14 \%)$ & $818 \quad(41 \%)$ \\
\hline $\begin{array}{l}\text { Normal weight } \\
\left(\text { BMI } 18.5-24.9 \mathrm{~kg} / \mathrm{m}^{2}\right)\end{array}$ & 779 & $638(82 \%)$ & 2.58 & $247 \quad(32 \%)$ & $214 \quad(27 \%)$ & 100 & $(13 \%)$ & $462^{\mathrm{d}, \mathrm{e}}(59 \%)$ \\
\hline $\begin{array}{l}\text { Overweight } \\
\left(\text { BMI } 25.0-29.9 \mathrm{~kg} / \mathrm{m}^{2}\right)\end{array}$ & 651 & $559(86 \%)$ & 2.65 & $272^{f} \quad(42 \%)$ & $326^{f} \quad(50 \%)$ & 92 & $(14 \%)$ & $230^{\mathrm{e}} \quad(35 \%)$ \\
\hline $\begin{array}{l}\text { Obese } \\
\left(\mathrm{BMI} \geq 30.0 \mathrm{~kg} / \mathrm{m}^{2}\right)\end{array}$ & 411 & $364^{f}(89 \%)$ & 3.47 & $233^{\mathrm{d}, \mathrm{f}}(57 \%)$ & $290^{\mathrm{d}, \mathrm{f}}(71 \%)$ & $73^{f}$ & $(18 \%)$ & $41 \quad(10 \%)$ \\
\hline $\begin{array}{l}\mathrm{BMI} \geq 30.0 \mathrm{~kg} / \mathrm{m}^{2} \text { with } \\
\text { no comorbidities }\end{array}$ & 221 & $178(81 \%)$ & 2.82 & $43 \quad(19 \%)$ & $139 \quad(63 \%)$ & 49 & $(22 \%)$ & $32 \quad(15 \%)$ \\
\hline $\begin{array}{l}\mathrm{BMI} \geq 27.0 \mathrm{~kg} / \mathrm{m}^{2} \text { with } \\
\text { comorbidities }\end{array}$ & 293 & $289(98 \%)$ & 3.96 & $293(100 \%)$ & $210 \quad(71 \%)$ & 43 & $(15 \%)$ & $40 \quad(14 \%)$ \\
\hline
\end{tabular}

Abbreviations: BMI, body mass index; $\mathrm{n}$, sample size; $p$, p-value.

${ }^{\mathrm{a}}$ Weighted data.

${ }^{\mathrm{b}}$ Based on all respondents, including those who said that they had not seen a physician in the last 12 months. Median number of visits $=2.0$.

${ }^{c}$ Data for underweight respondents $(n=52)$ or respondents who did not know or refused to provide their weight $(n=111)$ are included in these totals, but are not presented elsewhere in the table.

${ }^{\mathrm{d}}$ Significantly different from overweight respondents $(p<.05)$.

${ }^{\mathrm{e}}$ Significantly different from obese respondents $(p<.05)$.

${ }^{f}$ Significantly different from normal weight respondents $(p<.05)$.

$83 \%$ each), and an increase in the number of visits with increasing BMI. The highest consultation rate was seen in those with BMI of $27 \mathrm{~kg} / \mathrm{m}^{2}$ plus with comorbidities ( $\mathrm{n}=289 / 293 ; 98 \%$ ). The mean number of visits was based on all respondents, including those who said that they had not seen a physician in the previous 12 months; as a result, the median number of visits, 2.0, was also calculated.

While $67 \%$ of all respondents reported that they had not specifically asked a health care professional about losing weight ( $n=1339)$, of those that had $(n=665)$ $72 \%$ had consulted their family physician ( $\mathrm{n}=482), 24 \%$ consulted a dietitian ( $\mathrm{n}=158), 16 \%$ a nutritionist $(\mathrm{n}=108)$, $16 \%$ a nurse or nurse practitioner $(\mathrm{n}=107)$ and $9 \%$ a pharmacist $(n=59)$. Percentages do not add up to 100 as some respondents consulted more than one health care professional. Consultation rates were higher for women than men and increased across the age groups and with increasing BMI.

Only $15 \%$ of respondents had asked their family physician about weight loss ( $n=295$ ) in the 12 months before the survey; slightly more women (17\%) than men (13\%) sought such help. Again, there was a trend with increasing age, from $10 \%$ (18-24 years) to $18 \%$ ( $\geq 55$ years), and BMI, with $24 \%$ and $56 \%$ of the overweight and obese respondents having ever asked a physician about losing weight. Of these, around half had done so in the 12 months before the survey (i.e. $13 \%$ and $35 \%$ overweight and obese respondents, respectively).

Forty percent of all respondents reported being currently under the care of a physician for some condition ( $\mathrm{n}=808 / 2004)$. Slightly more women (44\%) than men (37\%) reported being currently under the care of a physician for any condition, and this increased with age, from 19\% in young adults (18-34 years) to $66 \%$ in older adults ( $\geq 55$ years). Similarly, there was an age-related increase in the percentage under care for specified weight-related comorbidities, ranging from $6 \%$ to $56 \%$. Around half of the respondents who were overweight ( $\mathrm{n}=272 / 651 ; 42 \%$ ) or obese ( $\mathrm{n}=233 / 411 ; 57 \%$ ) were under the care of a physician for any condition, with $30 \%$ and $46 \%$, respectively, for specified weight-related comorbidities ( $n=193$ and $\mathrm{n}=190$ respectively). Table 2 shows the self-reported prevalence of the most common medical conditions.

It is interesting to note that only $30 \%$ of overweight or obese respondents had been advised to lose weight without specifically asking their physician ( $\mathrm{n}=320 / 1062$ ). In $19 \%$ of overweight or obese respondents ( $n=197 / 1062$ ), this advice was understood to have been given to improve health in general, and in $12 \%$ ( $\mathrm{n}=123 / 1062)$, to improve the treatment of some other medical condition. This pattern was similar for men and for women. However, advice to lose weight was more often given to middle-aged (35-54 years; $21 \%$ ) and older adults ( $\geq 55$ years; $24 \%$ ) than younger adults (18-34 years; $11 \%$ ), and increased with increasing BMI (normal range, $5 \%$; overweight, $18 \%$; obese, $49 \%$ ), with advice given most frequently to those with a BMI of $27 \mathrm{~kg} / \mathrm{m}^{2}$ plus with comorbidities $(54 \%)$. Obese respondents understood that the advice to lose weight was meant to improve their overall health (30\%) and to improve the treatment of some other medical condition (19\%). Similarly, those with a BMI of $27 \mathrm{~kg} / \mathrm{m}^{2}$ plus with 
TABLE 2

Self-reported prevalence of common medical conditions by BMI category

\begin{tabular}{|c|c|c|c|c|}
\hline \multirow[t]{2}{*}{ Medical condition } & \multicolumn{4}{|c|}{ Respondents ${ }^{\mathrm{a}}$, n (\%) } \\
\hline & $\begin{array}{c}\text { All } \\
(n=2004)\end{array}$ & $\begin{array}{l}\text { Normal weight } \\
\quad(n=779)\end{array}$ & $\begin{array}{l}\text { Overweight }^{c} \\
(n=651)\end{array}$ & $\begin{array}{c}\text { Obese }^{d} \\
(n=411)\end{array}$ \\
\hline High blood pressure & $301(15)$ & 67 (9) & $99(15)^{\mathrm{e}}$ & $111(27)^{\mathrm{e}, \mathrm{f}}$ \\
\hline High cholesterol & $211(11)$ & $48 \quad(6)$ & $78(12)^{e}$ & $74(18)^{e, f}$ \\
\hline $\begin{array}{l}\text { Cardiovascular/heart } \\
\text { disease }\end{array}$ & $99 \quad(5)$ & 23 (3) & $35(5)^{e}$ & $33(8)^{e}$ \\
\hline Diabetes & 146 (7) & $35 \quad(5)$ & $51(8)^{e}$ & $55(13)^{e, f}$ \\
\hline Osteoarthritis & $134(7)$ & $36 \quad(5)$ & $43(7)$ & $51(12)^{e, f}$ \\
\hline Other & 369 (18) & 134 (17) & 116 (18) & $88(22)$ \\
\hline
\end{tabular}

Abbreviations: $\mathrm{BMI}$, body mass index; $\mathrm{n}$, sample size; $p$, $\mathrm{p}$-value.

${ }^{\mathrm{a}}$ Weighted data.

${ }^{\mathrm{b}} \mathrm{BMI}=18.5-24.9 \mathrm{~kg} / \mathrm{m}^{2}$.

${ }^{\mathrm{C}} \mathrm{BMI}=25.0-29.9 \mathrm{~kg} / \mathrm{m}^{2}$.

${ }^{\mathrm{d}} \mathrm{BMI} \geq 30.0 \mathrm{~kg} / \mathrm{m}^{2}$.

e Significantly different from normal weight respondents $(p<.05)$.

${ }^{\mathrm{f}}$ Significantly different from overweight respondents $(p<.05)$.

comorbidities understood that this advice had been given to improve health in general $(28 \%)$ and to improve the treatment of some other medical condition $(26 \%)$.

Of the 383 overweight or obese respondents who had requested a health care professional's support to lose weight, 15 (4\%) reported receiving no advice, while 261 (68\%) reported receiving dietary advice, 237 (62\%) reported receiving exercise advice, 47 (12\%) were advised to join a weight loss program, slimming club, or to take meal replacements or supplements, and 15 (4\%) were prescribed anti-obesity medication. Of the 230 obese respondents who had requested support to lose weight, 10 (4\%) reported being advised on options for surgery, as did one overweight individual.
Objective 2: Reported weight management practices of family physicians consistent with the Canadian Guidelines

We sought to determine whether survey respondents reported that their family physicians used weight management practices as recommended in the Guidelines. ${ }^{10}$ Table 3 shows the number of respondents who reported having their waist circumference measured in the previous 12 months as well as their blood pressure and blood glucose tested. Only $14 \%$ of respondents reported that a physician had measured their waist circumference $(n=285 / 2004)$; this was slightly higher for men $(17 \%)$ than women $(12 \%)$ and increased with age from $11 \%$ in younger adults (18-34 years) to $14 \%$ and $18 \%$ in middle-aged (35-54 years) and older adults ( $\geq 55$ years) respectively. Measuring waist circumference in the previous year was only slightly influenced by BMI (normal weight, $13 \%$; overweight, $14 \%$; obese, $18 \%$ ) and only marginally higher in those with BMI of $27 \mathrm{~kg} / \mathrm{m}^{2}$ plus with comorbidities (21\%) relative to the obese, although the difference between normal weight and obese respondents was significant. However, $84 \%$ of overweight or obese respondents had not had their waist circumference measured in the previous year $(\mathrm{n}=889 / 1062)$.

TABLE 3

Reported weight management practices of family physicians using three of the 2006 Canadian Clinical Practice Guidelines

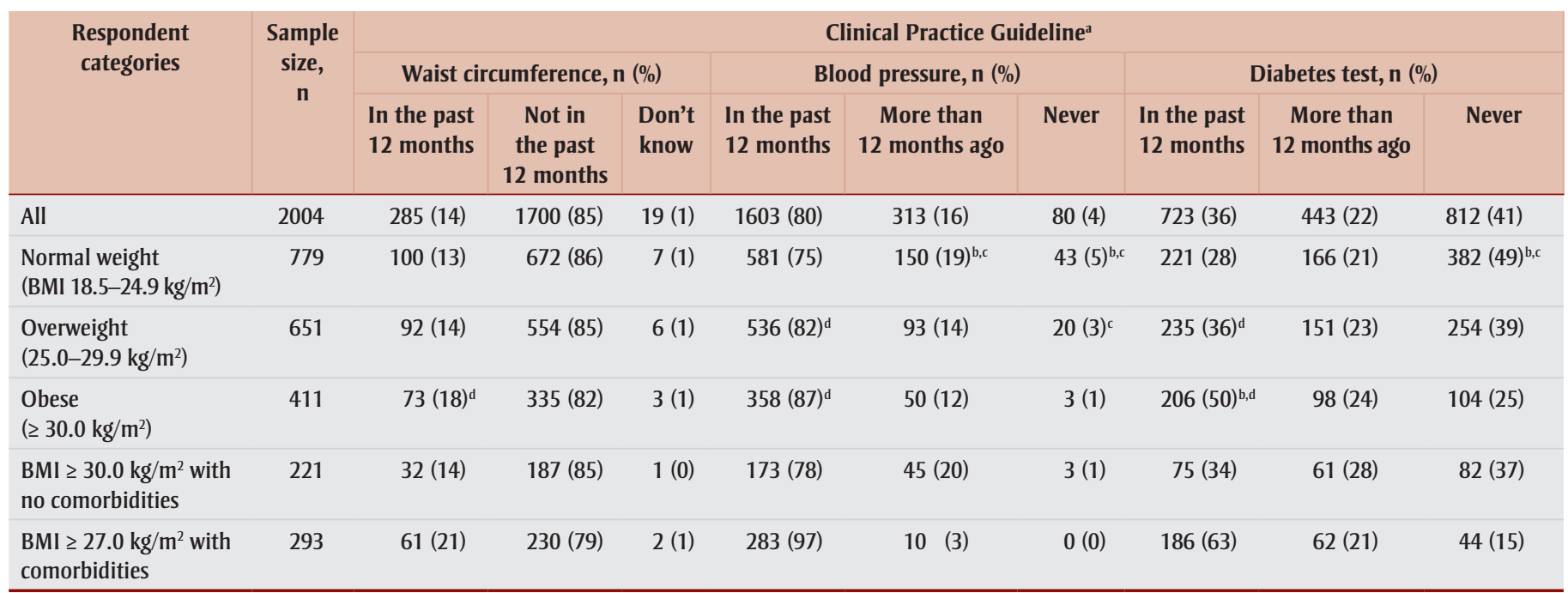

Abbreviations: BMI, body mass index; $\mathrm{n}$, sample size; $p$, $\mathrm{p}$-value.

${ }^{\mathrm{a}}$ Weighted data.

${ }^{\mathrm{b}}$ Significantly different from overweight respondents $(p<.05)$.

c Significantly different from obese respondents $(p<.05)$.

${ }^{\mathrm{d}}$ Significantly different from normal weight respondents $(p<.05)$. 
With regard to measuring blood pressure in the previous 12 months, there was a trend with gender and age. Slightly more women (85\%) than men $(75 \%)$ reported that their blood pressure was checked, and $69 \%$ of younger adults (18-34 years) compared to $90 \%$ of older adults ( $\geq 55$ years). The trend also increased with increasing BMI. Slightly more women (65\%) than men (51\%) reported ever having had a test for diabetes, and this also increased with age (40\% in those aged $18-34$ years up to $74 \%$ in those aged 55 years plus) and increased BMI (36\% of the overweight and $50 \%$ of the obese) in the previous 12 months. Differences were significant for both overweight and obese respondents compared with those in the normal weight category for blood pressure and diabetes testing within the previous 12 months.

\section{Discussion}

This survey offers insight into the current weight management experiences of Canadians and highlights the weight management practices of their physicians in relation to three of the recommendations of the 2006 Clinical Practice Guidelines. Of the survey respondents, $53 \%$ reported being overweight $(33 \%)$ or obese $(20 \%)$, slightly lower than published Canadian data (overweight, 36\%; obese, 23\%), ${ }^{1}$ possibly as a result of using self-reported data on height and weight (individuals typically underestimate self-reported weight and overestimate self-reported height. ${ }^{13}$ ) It is also interesting to note that $40 \%$ of overweight or obese respondents described themselves as "about right." This phenomenon has been found in other studies and may be due to the normalization of excessive weight gain as obesity rates rise. ${ }^{14,15}$ This has implications for health care professionals who may need to raise awareness of the health risks of overweight or obesity in their patients before offering any weight management advice.

While over half the survey respondents reported being overweight or obese, surprisingly few had asked for or received weight loss advice from a health care professional. The majority of survey respondents reported visiting their physician in the previous 12 months, significantly more so if they were obese, and almost three-quarters of the overweight and obese Canadian adults surveyed had tried to lose weight, $58 \%$ in the previous 12 months. Nevertheless, only $21 \%$ of overweight individuals reported seeking help from their physician in the previous year, suggesting that the majority viewed weight loss as their own responsibility. Moreover, less than one-third of overweight/ obese individuals had ever been advised to lose weight by a physician (without specifically asking), a further indication of the widely held societal view that obesity is an issue of personal responsibility rather than a medical problem. ${ }^{15}$ As a result, most weight loss attempts reported here were likely to have been initiated by the individual rather than as a result of advice from a health care professional, with diet and exercise being the two most frequent methods used. Support was also sought from dietitians, nurses and pharmacists, highlighting the role of these different health care professionals in weight management.

Of those overweight or obese individuals who did ask their physician about weight loss, they generally received advice on diet and exercise, with only $4 \%$ of obese individuals reporting receiving advice on surgery options. This is especially noteworthy given the promising role of surgery as the leading effective long-term treatment option for people with severe obesity. ${ }^{16,17}$ Although the criterion for considering surgery is a BMI of $40 \mathrm{~kg} / \mathrm{m}^{2}$ plus or $35 \mathrm{~kg} / \mathrm{m}^{2}$ plus with comorbidities, whereas our sample were classified as obese if they reported a BMI of $30 \mathrm{~kg} / \mathrm{m}^{2}$ and over, surgical interventions should be considered within a portfolio of options for obesity management, as outlined in the available Clinical Practice Guidelines. ${ }^{10}$

In Canada, there are considerable opportunities for physicians to screen for comorbidities and they do so routinely; $84 \%$ of overweight or obese Canadian adults had their blood pressure checked in the previous year, which is in line with the 2009 Recommendations of the Canadian Hypertension Education Program. ${ }^{18}$ Similarly, according to the Canadian Diabetes Association 2008 Clinical Practice Guidelines, individuals aged 40 years plus should be screened for type 2 diabetes using a fasting plasma glucose test every three years, while those with additional risk factors for diabetes should be screened earlier and/or more frequently. ${ }^{19}$ This survey found that $66 \%$ of overweight or obese Canadians reported ever being knowingly tested for diabetes. These findings are encouraging; however, there remains a need to address obesity earlier in the trajectory of weight gain to prevent the onset of chronic disease. ${ }^{1}$ While respondents reported that their physicians were following the main recommendations in the screening of hypertension and diabetes, this did not apply to the recommendations for assessing obesity by measuring waist circumference. ${ }^{10,18,19}$

Given the scale of the obesity epidemic, our findings highlight that surprisingly few overweight or obese patients reported receiving advice about weight management. This suggests that the health care system is not providing adequate obesity management services. ${ }^{9}$ This is in spite of obesity being increasingly prevalent ${ }^{3}$ and increasingly recognized as a disease state in its own right. ${ }^{8}$ One of the reasons that physicians may be more likely to address hypertension and/or diabetes than obesity could be because these are recognized as diseases, whereas obesity is still only considered a risk factor for disease. ${ }^{20}$ While this view has been challenged by obesity experts, ${ }^{21}$ obesity is not widely accepted as a disease, and this may constitute a barrier to improved management. Further, the prevalent societal view is that obesity is a condition caused by lack of willpower and that overweight and obese people are weak-willed, sloppy and lazy. ${ }^{22}$ These views are frequently shared by health care professionals and may interfere with how they engage overweight and obese individuals in discussing weight management. ${ }^{22}$ Addressing issues of bias and stigma associated with overweight and obesity may therefore improve how weight management advice is both offered and received within the health system. ${ }^{22}$

\section{Limitations}

Limitations to this study are the use of self-reported data; as previously outlined, self-reports are known to underestimate 
the prevalence of obesity. ${ }^{13}$ In addition, there was no objective measure of physician behaviour, although this survey does serve as a proxy measure by providing insight into the behaviour of health care professionals as reported by their patients. Respondents were not asked about their perceptions of the quality of their health care experiences or their interactions with health care providers, including whether they had experienced bias regarding their weight. ${ }^{22}$ Despite these limitations, given that advice from a physician is a powerful motivator for weight loss, ${ }^{23}$ the fact that overweight and obese individuals were not routinely encouraged to lose weight by their physicians is a cause for concern. Changing how health care professionals view and manage obesity is an area that has been poorly researched, as evidenced by the small number of studies included in a recent Cochrane systematic review on this topic. ${ }^{24}$ However, the available evidence does support the role of physicians and other health care professionals in obesity management, ${ }^{24}$ offering hope for the future management of this condition. Canadian physicians have expressed a need to spend more time with patients and to decrease the number of patients seen per hour. ${ }^{25}$ They are also willing to refer patients to other health care professionals, such as dietitians, although they have reported concerns with timely access to these professionals and see a need for a less time-consuming referral process. ${ }^{25}$ There is clearly a need for the current obesity guidelines to be more effectively implemented and evaluated, and for more resources to support implementation, particularly at the point of care. ${ }^{26}$ Finally, and perhaps most importantly, there is a need to overcome some of the issues of bias and stigma held widely by society, including health care professionals, ${ }^{22}$ and to recognize that obese people often present with a range of other issues that may hinder their ability to lose weight, including mental health issues, chronic pain and family or social barriers. ${ }^{27}$ While not measured within this survey, these issues are known to influence weight management initiation and maintenance. ${ }^{22,26}$ Health care professionals need to be aware of and supportive of these issues if we are to improve obesity management practices within the Canadian health care setting.

\section{Acknowledgements}

This survey was supported by an unconditional educational grant from Glaxo-Smith Kline to the Canadian Obesity Network.

\section{References}

1. Tjepkema M. Adult obesity. Health Rep. 2006;17(3):9-25.

2. World Health Organization. Obesity: preventing and managing the global epidemic - report of a WHO consultation. Geneva (CH): WHO; 1997 Jun. Report No.: WHO/NUT/NCD/98.1.

3. Anis AH, Zhang W, Bansback N, Guh DP, Amarsi Z, Birmingham CL. Obesity and overweight in Canada: an updated cost-of-illness study. Obes Rev. 2010;11(1):31-40.

4. Jia H, Lubetkin EI. Trends in quality-adjusted life-years lost contributed by smoking and obesity. Am J Prev Med. 2010;38(2):138-144.

5. Katzmarzyk PT, Mason C. Prevalence of class I, II and III obesity in Canada. CMAJ. 2006;174(2):156-7.

6. Block JP, DeSalvo KB, Fisher WP. Are physicians equipped to address the obesity epidemic? Knowledge and attitudes of internal medicine residents. Prev Med. 2003;36(6):669-75.

7. Epstein L, Ogden J. A qualitative study of GPs' views of treating obesity. $\mathrm{Br} \mathrm{J}$ Gen Pract. 2005;55(519):750-4.

8. Jackson JE, Doescher MP, Saver BG, Hart LG. Trends in professional advice to lose weight among obese adults, 1994 to 2000. J Gen Intern Med. 2005;20(9):814-8.

9. Padwal RS, Damjanovic S, Schulze KM, Lewanczuk RZ, Lau DC, Sharma AM. Canadian physicians' use of antiobesity drugs and their referral patterns to weight management programs or providers: the SOCCER study. J Obes. 2011;686521. Epub 2010 Nov 21. doi: 10.1155/2011/686521
10. Lau DC, Douketis JD, Morrison KM, Hramiak IM, Sharma AM, Ur E, et al. 2006 Canadian clinical practice guidelines on the management and prevention of obesity in adults and children [Internet]. CMAJ. 2007 [cited 2010 Dec];176(8):1103-6. Available from: http://www.cmaj.ca/cgi/content/full/ $176 / 8 /$ S1

11. McDonald SD. Management and prevention of obesity in adults and children. CMAJ. 2007;176(8):1109-10.

12. Canada Year Book 2008. Available from: http://www41.statcan.gc.ca/2008/ ceb_r000_2008-eng.htm

13. Visscher TL, Viet AL, Kroesbergen HT, Seidell JC. Underreporting of BMI in adults and its effect on obesity prevalence estimations in the period 1998 to 2001. Obesity. 2006;14:2054-63.

14. Johnson F, Cooke L, Croker H, Wardle J. Changing perceptions of weight in Great Britain: comparison of two population surveys. BMJ. 2008;337(7761):a494. doi: 10.1136/bmj.a494

15. Pulvers KM, Kaur H, Nollen NL, Greiner KA, Befort CA, Hall S, et al. Comparison of body perceptions between obese primary care patients and physicians: implications for practice. Patient Educ Couns. 2008;73(1):73-81.

16. Buchwald H, Avidor Y, Braunwald E, Jensen MD, Pories W, Fahrbach K, et al. Bariatric surgery: a systematic review and meta-analysis. JAMA. 2004;292(14):1724-37.

17. Livingston EH, Fink AS. Quality of life: cost and future of bariatric surgery. Arch Surg. 2003;138(4):383-8.

18. Canadian Hypertension Education Program. The 2008 Canadian Hypertension Education Program recommendations: the scientific summary - an annual update. Can J Cardiol. 2008;24(6):447-52.

19. Canadian Diabetes Association Clinical Practice Guidelines Expert Committee. Canadian Diabetes Association 2008 clinical practice guidelines for the prevention and management of diabetes in Canada. Can J Diabetes. 2008;32(suppl 1):S1-S201. 
20. Heshka S, Allison DB. Is obesity a disease? Int $\mathrm{J}$ Obes Relat Metab Disord. 2001;25:1401-4

21. The Council of the Obesity Society. Obesity as a disease: The Obesity Society Council Resolution. Obesity. 2008;16(6):1151. doi:10.1038/oby.2008.246.

22. Puhl RM, Heuer CA. The stigma of obesity: a review and update. Obesity. 2009;17(5):941-64. doi:10.1038/oby.2008.636

23. Loureiro ML, Nayga J,Rodolfo M. Obesity, weight loss, and physician's advice. Soc Sci Med. 2006 5;62(10):2458-68.

24. Flodgren G, Deane K, Dickinson HO, Kirk S, Alberti H, Beyer FR, et al. Interventions to change the behaviour of health professionals and the organisation of care to promote weight reduction in overweight and obese people [Internet]. Cochrane DB Syst Rev. 2010 [cited $2010 \mathrm{Dec}$; (3). Available from: www.mrw.interscience.wiley.com/cochrane/ clsysrev/articles/CD000984/frame.html doi: 10.1002/14651858.CD000984.pub2

25. Moores DG, Wilson DR, Cave AJ, Woodhead Lyons SC, Donoff MG. Improving the quality and capacity of Canada's health services: primary care physician perspectives. Healthc Policy. 2007;3(2):1-17.

26. Sharma AM, Kushner RF. A proposed clinical staging system for obesity. Int $\mathrm{J}$ Obes (Lond). 2009;33(3):289-95.

27. Mauro M, Taylor V, Wharton S, Sharma AM. Barriers to obesity treatment. Eur J Intern Med. 2008;19(3):173-80. 